\title{
Escola Secundária de Cantanhede
}

\author{
ENTREVISTA CONDUZIDA POR CARLOS FOLHADELA SIMÕES
}

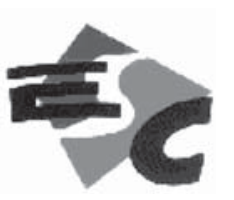

A Escola Secundária de Cantanhede nasceu com o 25 de Abril de 1974, ocupando as instalações da então Escola Comercial e Industrial (a funcionar no velho edifício do Hospital da Misericórdia e actual Centro de Dia para a terceira idade) e ainda as instalações do antigo Colégio Infante de
Sagres (presentemente o Centro de Saúde concelhio). No início do ano lectivo de 1977/78, a Escola instalou-se no actual edifício e, desde 1997/98, deixou de leccionar o 3. ${ }^{\circ}$ Ciclo do Ensino Básico, em regime diurno. Estivemos à conversa com o Eng. ${ }^{\circ}$ Vítor Gomes (VG), Coordenador de Departamento e com o Dr. António José Ferreira (AJF), Professor de Química.
Eng. ${ }^{\circ}$ Vítor Gomes, na impossibilidade de termos presente o Presidente do Conselho Executivo agradecia que nos apresentasse a escola

VG - A Escola está situada no concelho de Cantanhede que é composto por 168 povoações distribuídas por 19 freguesias. O Concelho é o centro do triângulo formado por Coimbra, Figueira da Foz e Aveiro.

Que cursos ministram?

VG - Temos cursos Científico-Humanisticos: Artes Visuais, Ciências Sociais e Humanas, Ciências e Tecnologias e Ciências Sócio-económicas. Temos ainda quatro cursos tecnológicos, um profissional e quatro cursos de educação e formação, um dos quais é o curso de Técnico de Análise Laboratorial. Temos no ensino nocturno cursos de módulos capitalizáveis e ensino recorrente.

Como definiria a escola que pretendem?

VG - Creio que poderá ser resumida pelo que temos no projecto educativo: "... Não queremos uma escola que se preocupe exclusivamente com o "aprender a conhecer" e com o "aprender a fazer" mas que também se empenhe, de forma sistemáti- ca, a desenvolver o "aprender a viver em comum" e o "aprender a ser". A formação integral do aluno só será possível se a escola se assumir como comunidade de educação, relação e realização, isto é, se as famílias não deixarem de exercer o seu papel fundamental na educação e acompanhamento dos filhos, se os professores se empenharem na inovação educativa, se os funcionários privilegiarem, no seu trabalho, o desenvolvimento de atitudes formativas dos alunos e se estes entenderem, como finalidade da sua presença na escola, desenvolver aptidões para se transformarem em cidadãos intervenientes nas comunidades locais e no desenvolvimento do seu país. (...)"

Um dos temas da actualidade é o ressurgimento do Programa Ciência Viva. Como o entendem?

AJF - Essa notícia para nós é óptima. Foi um programa que serviu para desenvolver um importante conjunto de actividades. Como é óbvio, vejo esse ressurgimento com muito agrado. Gostaria de frisar que não só para nós como também para as escolas em geral.

Quais as vossas participações anteriores?
AJF - Estivemos no Ciência Viva I, através de uma participação em parceria...

VG - ...sim, com a Universidade de Coimbra (Departamento de Física)...

AJF - ...depois no II já participámos com projectos próprios. Creio que na altura em número de cinco. Foi uma oportunidade de dotar a escola com determinado tipo de equipamento e não poderíamos deixar fugir a oportunidade. O Departamento de Ciências Físico-Químicas não participou no III, embora a escola o tenha feito. No Ciência Viva IV apresentamos um projecto já com a preocupação de envolver entidades exteriores à escola e com uma muito maior preocupação com aspectos pedagógicos, isto é, desenvolver determinado tipo de capacidades e competências nos alunos que participavam nesses projectos. Para eles foi muito mais claro que estavam a participar no Ciência Viva e quais eram os objectivos dessa participação.

As parcerias que referiu foram efectuadas com que entidades?

AJF - Com a Câmara Municipal de Cantanhede, com a Adega Cooperativa de Cantanhede e com o Grupo Fiscal de Coimbra da Guarda Nacional Republicana. 
Quais as temáticas dos vossos projectos...

AJF - Eram relacionados com análise química. Havia um determinado tipo de problemas da instituição parceira, que estava ligado à necessidade de fazer análises químicas e nós mostramos isso aos nossos alunos: que tipo de problemas se colocavam e como a análise química poderia ser utilizada para os ultrapassar.

VG - O objectivo básico era mesmo esse.

Qual a postura dos alunos face a esses projectos que normalmente são desenvolvidos para além do currículo?

VG - No nosso caso não foram. Tivemos, e temos, alguma dificuldade em conseguir isso. Os alunos não têm grande disponibilidade para além do horário escolar...

AJF - ...desenvolvemo-los nas aulas de TLQ (Técnicas Laboratoriais de Química). Esta é uma escola só do ensino secundário e temos algumas dificuldades em mobilizar os nossos alunos para actividades extra-curriculares, do género dos clubes, já que têm uma carga de trabalho considerável. Na altura, os projectos foram desenhados para as aulas de Técnicas Laboratoriais de Química e de Ciências Físico-Químicas. Foram quase sempre desenvolvidos como actividades curriculares.

Poderá a participação no Ciência Viva VI estar de algum modo comprometida com o desaparecimento das técnicas ou encontrarão outra forma de desenvolver as actividades?

AJF - Há que encontrar outra forma de fazer as coisas, pois teremos com certeza algumas dificuldades de fazer projectos baseados no modelo anterior.

Entendem que também por isso o desaparecimento das técnicas é negativo...

AJF - Acho que desapareceram as TLQ e não apareceu mais nada...pensou-se na implementação da Área de Projecto mas neste momento ela está confinada ao $12{ }^{\circ}$ ano. A área de projecto poderia ser aproveitada para desenvolver projectos e trabalhos na área das ciências... ...tem um mestrado nessa área...

AJF - Sim, a minha dissertação foi nessa área: como aproveitar as Áreas de Projecto para trabalhar em ciência. A área de projecto seria uma forma razoável de ultrapassar o fim das TLQ mas também acabou por se ficar pela intenção. Neste momento resta-nos a disciplina de Física e Química e acredito que aí os alunos não tenham muito tempo para as actividades de projecto.

Contudo, no Ciência Viva VI, continuaremos a fazer projectos na área curricular...

VG - ...na área curricular, exactamente. Aproveitaremos quer as aulas do $12{ }^{\circ}$ ano de Química e de Física, quer dos outros anos, para abordar alguns temas sob a forma de projecto. Claro que será complicado não contar com as técnicas, que era um espaço exclusivamente, ou quase exclusivamente, para a área experimental. Agora não. Temos a parte experimental intercalada com a teórica o que torna mais complicado conciliar as duas vertentes.

Têm problemas de espaços para permitir essa articulação de forma a que todos possam desenvolver trabalho experimental adequado?

VG - De certo modo não. Temos tido uma diminuição do número de alunos e temos dois laboratórios de química e duas salas que funcionam como laboratórios de física apesar de não estarem equipadas...

\section{...como assim..}

VG - ...temos salas normais que são transformáveis em laboratórios, onde colocamos o material sempre que precisamos...o que não se passa na química. Não temos tido, ainda, muito problema com os espaços...

AJF - ...será necessário referir que tem havido uma preocupação na elaboração dos horários para que tal seja possível...

VG - ...temos manifestado à comissão de horários a necessidade de colocar cada turma, pelo menos uma vez por semana, nos laboratórios...
AJF - . ..temos também as turmas desdobradas o que é extremamente importante para a realização de aulas práticas.

E o Conselho Executivo tem-vos apoiado na aquisição de material, equipamentos, consumíveis...Dá-vos um apoio efectivo?

VG - Eu diria que muito positivo tendo em atenção o que se vai ouvindo relativamente a outras escolas do país...

AJF - ...o nosso Conselho Executivo tem sido atencioso, vendo o nosso trabalho e o nosso empenhamento, tem dado resposta eficaz. A verdade é que procura sempre que não nos falte nada.

VG - Consumíveis temos sempre. Equipamento é que ainda nos falta algum...

AJF - . . mas a escola faz o esforço para ir adquirindo algum e de ir colmatando as deficiências.

VG - Com a aquisição que tem sido feita e com articulação e cooperação conseguimos dar resposta ao que é pedido nos vários anos.

\section{Participaram noutras actividades?}

AJF - Sim, na sequência das participações anteriormente referidas, entrei com uma turma no concurso «Jovem Consumidor Europeu» e tivemos a felicidade de ganhar um primeiro prémio a nível nacional no respectivo escalão etário. É uma coisa que é...

...motivante...

AJF - ...sim, extremamente motivante. Para os alunos é uma coisa que Ihes fica marcada no currículo e é bom que o comecem a construir desde cedo. Mas o mais importante é, de facto, a experiência adquirida.

\section{E em que consistiu?}

AJF - Era um trabalho sobre bebidas alcoólicas ou não estivéssemos nós na Bairrada...

...(risos)... Abordámos o tema em diversas dimensões: desde a que se relacionava com a saúde, decorrente da prática da ingestão de bebidas, até a parte laboratorial e às diversas análises que podem ser efectuadas. O que espero, como professor, é que este trabalho 


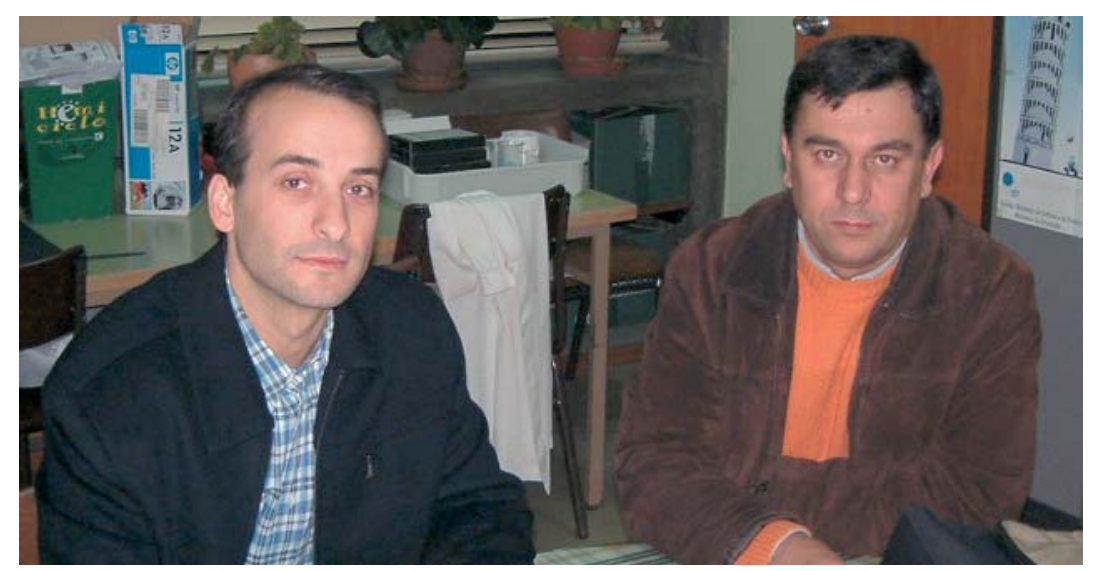

António José Ferreira (à esquerda), Professor de Química e Vítor Gomes, Coordenador de Departamento (à direita).

torne esses alunos mais conscientes relativamente à ingestão deste tipo de bebidas.

É também por isso que estão sempre dispostos a aproveitar as oportunidades e desafios lançados?

AJF - Sim, mas tem de haver sempre um enquadramento. Esse projecto foi desenvolvido por uma turma nas aulas de TLQ. O problema que sentimos hoje (o Vítor também pode falar sobre isso) é que, com os novos programas há falta de tempo para realizar este tipo de actividades. Aqui na escola estamos todos de acordo num ponto: os programas são grandes e isso dificulta muito a gestão e a realização de actividades que envolvam mais os alunos como, por exemplo: a participação em projectos, a realização de trabalhos de componente prático-laboratorial, trabalhos de pesquisa, etc. Sentimos que isso fica, no conjunto, comprometido por um programa que é muito extenso...

...o que retira algum espaço de manobra...

AJF - ...sim, embora acredite que ainda se possa optimizar esta gestão. Mas, de facto, o detalhe de alguns conteúdos e objectivos induz o professor num caminho que é muito estreito. Se esse detaIhe estivesse nas sugestões metodológicas, as ideias estavam presentes mas não tornava tão difícil para o professor cumprir o programa. Creio, aliás, que esta é uma marca do ensino secundário, os professores preocupam-se, julgo que sobretudo por uma questão de profissionalismo, em cumprir os programas... ...pois, mas há exames no final...

AJF - ...também por haver exames, mas acho que mais pela cultura profissional. Os professores do secundário têm por hábito cumprir os programas e serem meticulosos na forma como o cumprem. Os programas actuais são tão detalhados que nos obrigam a seguir o tal caminho estreito a que me referi, o que retira oportunidade para abordagens mais inovadoras. Temos notado que, em abordagens que se preconizam mais activas e em que se possa envolver mais os alunos, o que acaba por faltar não são as ideias mas o tempo. Temos tido a preocupação de cumprir a componente laboratorial mas muitas vezes sentimos que corremos, corremos, corremos... fazemos a actividade, mas não quer dizer que os alunos estejam a aprender, que estejam a apreender, que estejam a aproveitar...não há tempo para maturar...

...para os alunos é uma mistura da teórica com a prática enquanto as técnicas eram claramente práticas...

AJF - Sim e há trabalhos práticos que envolvem muitos aspectos teóricos e alguns deles que não estão ligados à componente teórica. Digamos que há muitos aspectos teóricos da própria prática...

...claro...

AJF - . .eé uma gestão bastante difícil sobretudo em termos de tempo. Conside- ro, no entanto, que estes programas são mais motivadores, são mais adequados àquilo que se pretende hoje para o ensino secundário. São mais estimulantes para os alunos e para nós. Mas esbarram com um problema que é incontornável: para fazer o que se preconiza no programa precisamos de mais tempo.

VG - Parece-me que a nossa formação e os nossos hábitos, com estes programas, estão um bocado comprometidos. Nós também não tivemos tempo para fazer formação adequada a estes programas.

Temos tido, no departamento, todos os anos, acções promovidas pelo centro de formação, nomeadamente na área laboratorial dos novos programas. Mas sentimos que não temos ainda tempo de formação suficiente para dar o programa como ele é preconizado.

Creio que os programas foram implementados muito em cima, sem experimentação anterior. Foram implementados e agora nós é que temos de nos "desenrascar".

Qual a preparação com que ingressam na escola os alunos provenientes do 3. ${ }^{\circ}$ ciclo?

VG - ...muito mal...

AJF - ...não entendo que seja muito mal. Acho que é antes muito heterogénea...

VG - ...ah, sim, sim...

AJF - ...o que nos obriga a partir quase do zero. Se, numa turma de vinte cinco alunos, há cinco ou seis que nunca fizeram uma decantação ou uma filtração, isso obriga-nos a começar do zero. E outros há que afirmam já o ter feito mas que não se lembram. Como estamos numa escola só com secundário não podemos preparar os nossos alunos a partir do básico.

Mas têm contactos com as escolas de que são provenientes?

AJF - São várias escolas. Não temos tido nenhum contacto em especial. A escola não funciona como agrupamento e como tal não temos tido esses contactos. 
Juntou-se a nós o Dr. Carlos Pedro (CP), um dos professores que leccionam o curso de Técnico de Análise Laboratorial. Dr. Carlos Pedro qual a importância destes cursos na área da química?

CP - Cada vez se fala mais na falta de técnicos intermédios. Tenho pouco conhecimento da realidade na área da indústria mas tenho a noção que há um défice de técnicos no patamar intermédio. $\mathrm{O}$ engenheiro ou o químico industrial acaba por fazer quase tudo, desde a preparação de soluções até à resolução de situações mais complexas. A preparação destes alunos vai nesse sentido: o de os habilitar a poderem preencher essa lacuna. Ainda há instantes Ihes dizia: "...vocês têm de preparar soluções tão bem como respiram...". Creio que o facto de poderem ficar habilitados a preparar as coisas mais simples Ihes abrirá várias portas no mundo do trabaIho. Mas um aspecto interessante destes cursos é o facto de serem uma alternativa para a conclusão do $12 .^{\circ}$ ano.

VG - São miúdos com muitas dificuldades ao nível da Matemática e mesmo da Química. Este curso tipo VI vai-Ihes permitir, de algum modo, colocá-los no mundo do trabalho.

CP - Ficam com equivalência ao $12 .^{\circ} \mathrm{e}$ habilitados para o exercício de uma profissão...

VG - ...com diploma de nível 3.

\section{É o primeiro ano que funciona?}

VG - Sim, é.

AJF - Temos de ver o que irá acontecer a nível de estágio. Temos já contactos estabelecidos, mas ainda nada formalizado. O estágio será um momento importante de afirmação dos alunos e será com certeza uma porta de entrada no mercado de trabalho. Vamos ver se levamos a bom porto esta tarefa. Falta saber se o discurso de falta de técnicos, da necessidade da indústria relativamente a estes profissionais, é efectiva.

VG - Formar, formamos. Esperemos que haja resposta do exterior. Noutras áreas o mercado tem absorvido. Na química, como é a primeira vez, estamos na expectativa. A zona não tem muita indús-

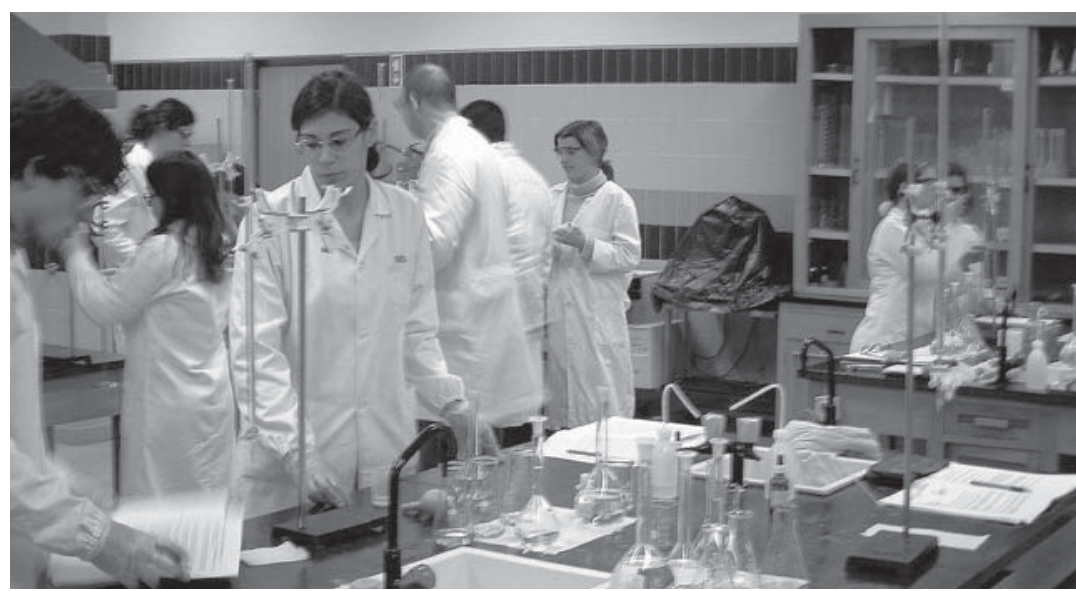

Aspecto de uma aula técnico laboratorial

tria química mas esperemos que surjam outras situações...

CP - ...também não será forçoso que seja nessa área. Temos as celuloses, a cimenteira em Souselas, algumas pequenas indústrias que os podem absorver até no controle de qualidade.

São alunos que frequentaram, no ano transacto, $012 .^{\circ}$ ano?

AJF - São alunos que têm de estar em condições de frequentar o $12 .^{\circ}$ ano...

$\mathrm{CP}$ - ... a maioria são alunos que já frequentaram o $12{ }^{\circ}$ sem o concluírem. Só duas alunas é que procedem do $11 .^{\circ}$. Temos dois alunos que procedem da área de economia...

Aí é formar de base. É idêntico ao que se passa com os alunos do $3 .^{\circ}$ ciclo. Temos de começar de início: escrita de fórmulas químicas, cálculos de massas molares...

...o que só se aborda no final do $100^{\circ}$ ano. Estará certo?

VG - Pois, fala-se no final do $10 .^{\circ}$ a correr e obrigam-se os alunos a dominar 0 cálculo estequiométrico no $11 .^{\circ} \ldots$

AJF - Não me escandaliza que se não dê no básico. Se o básico é formação geral e muitos deles não vão seguir cursos de ciências... Mas isso deve ser levado em consideração quando eles seguem estudos na área das ciências. Tem de haver tempo necessário para eles aprenderem esses conteúdos. Têm de ter tempo para maturar as coisas de outra forma. O que me escandaliza é ter meio bloco, ou um bloco, para trabalhar este conteúdo...
Que projectos têm para o futuro?

AJF - Levar este novo curso, de Técnico de Análise Laboratorial, a bom porto. De momento é o nosso maior desafio.

Sei que é co-autor de manuais, mas talvez mais relevante, que é autor de um kit para análise de plásticos, matéria abordada nos novos programas de $12 .^{\circ}$. Como surgiu esta iniciativa?

AJF - Surgiu a partir de um concurso para kits experimentais de ciência do Exploratório Infante D. Henrique. $\mathrm{Na}$ altura, concorri com uma ideia que achava interessante: um kit de análise de plásticos. Foi desenvolvido e levado a concurso com outros trabalhos que, na altura, tiveram melhor sorte! Tive, de seguida, a preocupação de Ihe dar um cunho mais profissional. Entrei em contacto com uma empresa que se disponibilizou a desenvolvê-lo de um ponto de vista comercial. É isso que está de momento disponível.

Devo realçar que a marcha de análise do kit não corresponde rigorosamente à que está no programa. É diferente mas não deixa de ser uma proposta de trabaIho interessante. Espero que possa ser útil. É a minha expectativa...

\section{E os interessados onde poderão obter} mais informação?

AJF - Na minha página pessoal, chamada «Química na Web» (http://quimicana-web.planetaclix.pt). Existe uma parte sobre análise de plásticos, com diversos trabalhos práticos e informações sobre o kit. 